Acta Scientifica Malaysia (ASM)

DOI: http://doi.org/10.26480/asm.01.2020.04.08

ZIBELINE INTERNATIONAL

ISSN: 2521-5051 (Print)

ISSN: 2521-506X (Online)

CODEN: $A S M C C Q$

RESEARCH ARTICLE

\title{
SPATIAL-TEMPORAL VARIATION AS AN EFFECTIVE SOCIO-ECONOMIC IMPACT OF POPULATION GROWTH IN MARARABAN GURUKU, NASARAWA STATE NIGERIA
}

\author{
Ibrahim Sufiyan, Jummai H.H., Magaji J I, K.D Mohammed \\ Nasarawa State University Keffi, Nasarawa Nigeria, Department of Geography. \\ *Corresponding Author Email: ibrahimsufiyan0@gmail.com
}

This is an open access article distributed under the Creative Commons Attribution License CC BY 4.0, which permits unrestricted use, distribution, and reproduction in any medium, provided the original work is properly cited

\section{ARTICLE DETAILS}

\section{Article History:}

Received 01 December 2019

Accepted 06 January 2020

Available online 21 January 2020

\begin{abstract}
One of the determinants of people's numbers is the socioeconomic prosperities of a particular place in the context of population census. The population is defined as the total number of people, animals and other variables per unit area in the environment. This study focuses on the negative and positive aspects of population growth and distribution. The study also covers possible factors influencing population growth and distribution in Mararaban Guruku, Karu Local Government Area of Nasarawa State. The data presented were obtained from the National Population Commission with a focus on socio-economic data and made use of appropriate statistical analysis of coefficient of determination ( $\left.\mathrm{R}^{2}\right)$. Almost all the models have a strong and significant correlation. The multiple regression analysis defined the fitness the model at 0.9 and 0.8 . The result indicates positive correlation of dependency ratio and strong impact on population increase. Mararaban Guruku is considered to have high population growth and subjected to negative influence population change ranging from high crime rate, growth of urban slums and ghetto, unemployment and overcrowding. However, it is suggested by the respondents that people are becoming aware of the use of family planning as an effective avenue of Birth control.
\end{abstract}

\section{KEYWORDS}

Climate Variation, Population, Socio-economic, Impact, Birth Rate.

\section{INTRODUCTION}

According a study, the population is simple to define as the number of humans, animals or plant species living in a particular environment, coexist and tolerate one another (Stephenson, et al., 2010). Population growth is a dynamic issue that is affected by climate. The population has both negative and positive impacts on humans and the environment. The population is defined as the number or entire group of people, farmland different crop events or measurements that have a common future (Obioha, 2008). Population density is a measurement of population per unit area, or exceptionally unit volume; it is a quantity of type number density. It is frequently applied to living organisms and most of the time to humans.

It is a key geographical term (Obioha, 2008). Population distribution is simply the pattern where people reside and live. Population distribution is uneven. There is a place in the world that is densely populated while others might have a sparse population. The hostile environment such as Antarctica where habitation is difficult is sparsely populated. Europe which is habitable is densely populated. Population Density: This is the number of people measured in a given area. It is simply defined as the total number of people per unit area, usually in a square kilometer. Areas of high population density tend to be located between $20^{\circ}$ and $60^{\circ} \mathrm{N}$. These are the temperate regions with a temperate climate. Two significant factors play an important role in affecting the population density (Adenola and Saibu, 2017):

1. Natural or physical factors

2. Human or Anthropogenic factors

The relief or topography is associated with the climate as a physical factor. The Ganges valley in India is considered as the lowland occupied by many large populations. The population is high in the flat land than in the highlands area occupied by the resource example like the tin mine in Jos, Coal in Enugu and oil in the creak of Nigeria. Area such as in the UK, climatic factor is relevant, the temperate climate helps in crop production. Heat and rain contribute to the dense population (Abu, et al., 2015).

\subsection{Spatio-Temporal Population Dynamics Model}

the preliminary version of a conceptual model is presented that facilitates a general implementation of population disaggregation processes. It is based on the assumption that population data, aggregated to a region, can be redistributed within the region by means of local parameters. These local parameters are usually represented by information on land use (residential housing densities, commercial areas, transport lines, etc.). Depending on the level of detail of these proxy parameters the actual spatial distribution of population can be estimated with more or less accuracy. The most straightforward approach to population disaggregation is the estimation of refined residential population

\begin{tabular}{|c|c|c|}
\hline Quick Response Code & \multicolumn{2}{|c|}{ Access this article online } \\
\hline DOI: & Website: & Do.26480/asm.01.2020.04.08 \\
\hline
\end{tabular}


distribution patterns. Population data available per administrative unit (census tract, municipality, etc. is disaggregated to actual settlement areas as e.g. identified in remote sensing imagery (Aubrecht, et al., 2014).

This approach is based on the assumption that settlement and, in a more refined perspective, housing density is correlated with population density. The resulting population data set still represents the nighttime population. In order to account for population dynamics and estimate the daytime population, the model needs to be conceptually extended. First, the total population per administrative 'input' unit may change in basic terms over the day due to people commuting in and out of the area. The disaggregation approach, therefore, requires a daytime dependent variable (temporal unit) in order to consider the diurnal variation of total population to be redistributed (e.g., hourly time steps). In addition to the varying total population numbers, implicit information on the dynamic changes of people's location is required. A group researcher presented a sort of binary approach assuming that people are in their workplaces/schools during the day and at home during the night, thus coming up with a basic nighttime/daytime population distribution model (Ali, et al., 2016)

\subsection{Impact of socio-economic activities on Population Growth}

Rapid population growth an increase might lead to the poor economy, reduction in agricultural output which resulted in food insecurity and the rate of fertility will be high causing a decline in per head income. Basic necessities Nigeria becomes a problem with low quality of energy and other services (Abubakar and Dano, 2018). There is a serious danger of the population growth rate in Nigeria. To appreciate this there is a need to address the issues of the impact of population growth in Nigeria. These impacts include:
1. Rapid urbanization
2. Land degradation
3. Waste Management
4. Water pollution
5. Climatic factor
6. Energy consumption
7. Soil
8. Drought
9. Oil spillage
10. Desertification

\subsection{Factors affecting Population}

Population control is required for obvious reasons (Theodore, 2006). These factors include:
1. religion
2. male-child preference
3. lack of education
4. the high infant mortality rate
5. Demographic Data
6. Social security

\subsection{Demographic transition}

The demographic transition of the population is showing the changes that occur during the process of population growth in the form of a model (Cole and Neumayer, 2004).

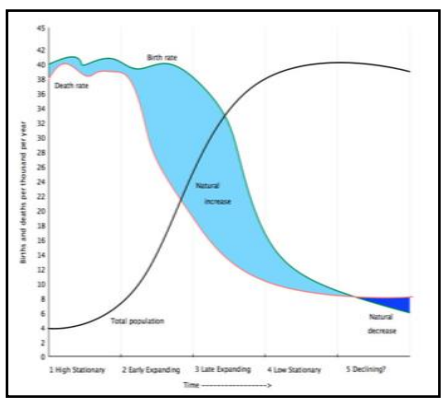

Figure 1: Demographic Model
Figure 1 Demographic Transition Chart (Davis, 1945). The demographic model denotes the stage of different change taking place in a given population.

These stages include:

1. Stage 1: both birth rates and death rates remain very high. The result is to have a low total population and low natural increase

2. Stage 2: The birth rate is high, and the death rate is low or falling. The result is the recording of high population growth (high natural increase)

3. Stage 3: low or falling in birth rate and low death rate. The result is a high natural increase (population growth)

4. Stage 4: both the birth rate and the death rate are low. The result is to have a high total population and low natural increase.

\section{Materials And Methods}

Mararaba Guruku is located at Lat $9^{\circ} 1^{\prime} 35.91^{\prime \prime N}$, Lon7 $7^{\circ} 36^{\prime} 6.44^{\prime \prime} \mathrm{E}$, and Lat $9^{\circ} 2^{\prime} 11.77^{\prime \prime} \mathrm{N}$, Long $7^{\circ} 37^{\prime} 19.12^{\prime \prime E}$. Mararaba is a town of urban settlement under Karu Local Government Area of Nasarawa State Nigeria, it is considered to be a district and become conurbation due to its proximity with the Federal Capital Territory. Mararaba is bounded by Ado, New Nyanya, Masaka and new Karu. The study area consists of different ethnic groups that live together. The major people occupying Mararaba Guruku includes the Gbagyi, Yeskwa, Koro, Mada, Hausa-Fulani, Gwandara, Gade. Other settlers are the Ibos, Yorubas, Tiv, Eggon who migrated for economic purposes and other opportunities.

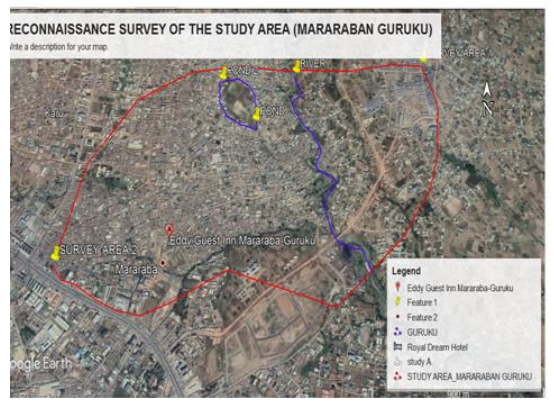

Figure 2: Satellite Image showing the Study Area

The primary source of data was collected using a questionnaire. The questionnaire survey was randomly distributed to cover the scope of the study. It was administered in the field. About 100 samples of the farmers' responses are collected. Most of the information regarding the population of the study area was obtained from the National population commission. The field survey employed the use of random sampling so that the study area will be fully represented. About the selection of the sample, every fifth of the houses was picked at random while two hundred (200) samples of households within the study area are selected.

The measuring instrument for this study is the use of appropriate statistical analysis. The two variable dependent and independent variables could be measured using multiple regression analysis. The test of the hypothesis base on the significance of the coefficient of determination (R2) is employed.

\section{RESULTS AND DISCUSSION}

\begin{tabular}{|c|c|c|c|}
\hline \multicolumn{4}{|c|}{ Table 1: Dependency Ratio of Mararaba Population } \\
\hline S/no & Dependency Ratio & Respondents & Percentage \\
\hline 1 & 1 & 20 & 20 \\
\hline 2 & 5 & 35 & 35 \\
\hline 3 & 10 & 15 & 15 \\
\hline 4 & 15 & 8 & 8 \\
\hline 5 & 20 & 5 & 5 \\
\hline 6 & 25 & 5 & 5 \\
\hline 7 & 30 & 2 & 2 \\
\hline \multicolumn{2}{|c|}{ Total } & 100 & $100 \%$ \\
\hline
\end{tabular}




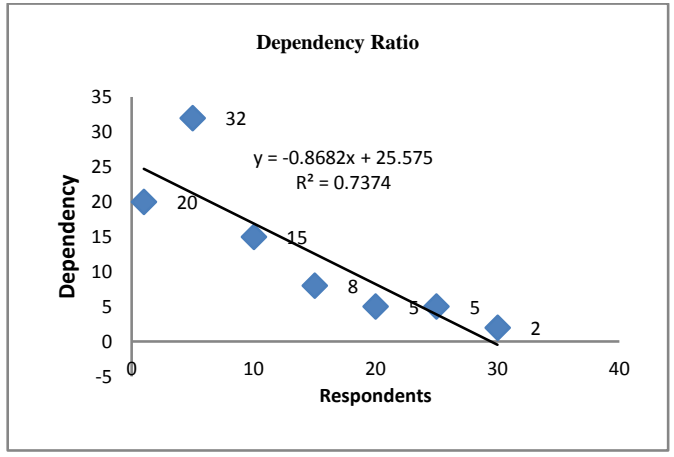

Figure 3: Equation of Dependency Ratio

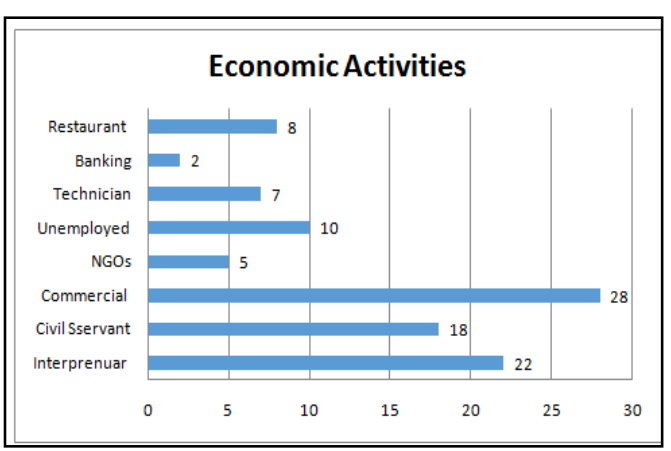

Figure 4: Bar graph of influence of Economy to Population Growth

There major significant correlation between economic activities and the growth in population. People tend to move and settle in an open up new economy, employment opportunities, or proximity to Federal or State capitals. However, Mararaba is located near the Federal Capital Territory (FCT Abuja).

\begin{tabular}{|c|l|c|c|}
\hline \multicolumn{3}{|c|}{ Table 2: Impacts of Population Growth in Mararaban Guruku } \\
\hline S/no & Impacts & Population Growth & Respondents \\
\hline 1 & Rapid Urbanization & 50 & 24 \\
\hline 2 & $\begin{array}{l}\text { Improved } \\
\text { Socioeconomic } \\
\text { Growth }\end{array}$ & 60 & 31 \\
\hline 3 & $\begin{array}{l}\text { Increase GDP Through } \\
\text { Taxation }\end{array}$ & 35 & 20 \\
\hline 4 & Increase in crime rate & 30 & 15 \\
\hline 5 & Insecurity & 25 & 10 \\
\hline \multicolumn{2}{|c|}{ Total } & 200 & 100 \\
\hline
\end{tabular}

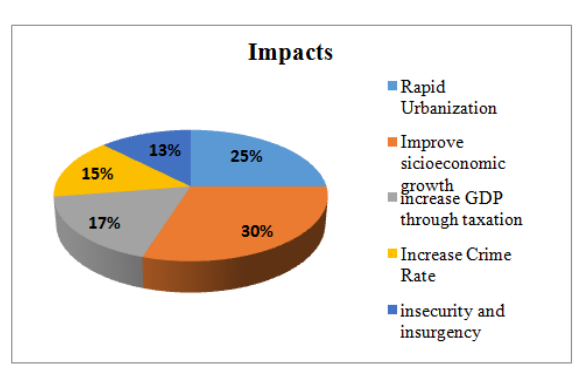

Figure 5: Pie chart showing impact of Population

Many cities in the world attract people in different ways. Abuja is not excluded, Mararaba Guruku has comparative advantages due to closeness to Abuja, the social events and the nature and attitude of people have influenced population growth. About 200 samples described the most influential social activities that socialize the people. The highest social event is a celebration conducted by people at different times. Here more people are invited some may decide to settle afterward with over $35 \%$. The religion such as Islam and Christianity are predominant, it also attracts the growth of the population with $24 \%$, and others include annual festival $10 \%$, inter-marraige $16 \%$, and local gathering $15 \%$ as shown in Table 2 .

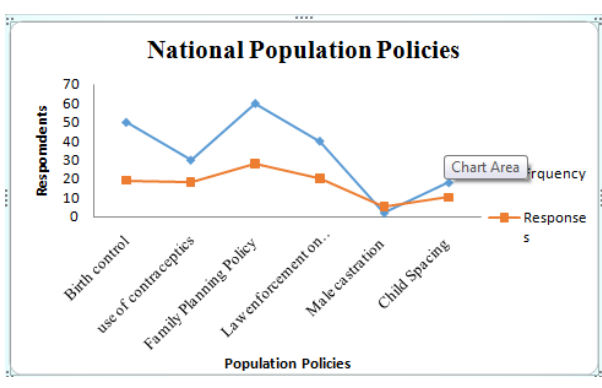

Table 6: Statistical Analysis showing Correlation and Regression Analysis

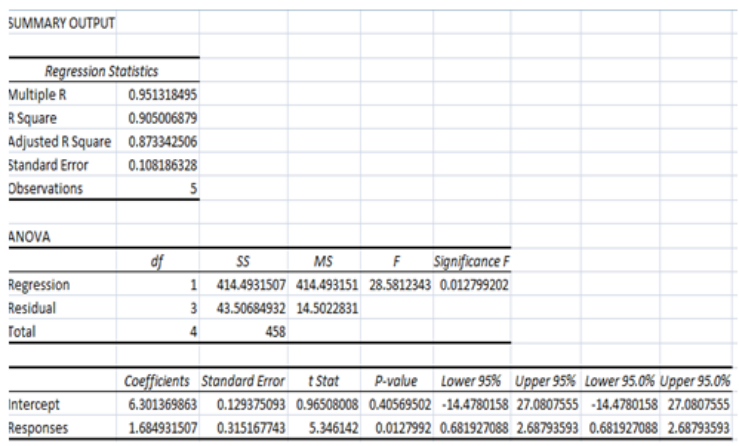

Figure 7: Regression Analysis

The model is strongly significant at 0.951318 as shown in the summary figure 7. Figure 7 is the graphic presentation showing the Regression equation. There are perfect relationships between social factors and population growth. The social value respondents have 0.9 coefficient of determination that social factors are affecting population growth and distribution. The population growth has 0.7 this signifies that the model fitted the equation. And the correlation coefficient has a significant relationship with 0.91 as shown in the 4.6.

\subsection{Model formulation}

Blancher's model specifies that total output $(\mathrm{Y})$ is a function of an economically active population or the labor force (L). This is expressed algebraically as follows

$\mathrm{Y}=\mathrm{L}(\mathrm{t}) \exp \mathrm{B}(\mathrm{t}) \quad 1$

The relationship in equation 1 can be rewritten in terms of per capita income as follows;

$\mathrm{dy} / \mathrm{y}=\alpha+\beta \mathrm{dL} / \mathrm{L} \quad 2$

If we incorporate into equation 2 the growth rate of population $(\mathrm{dp} / \mathrm{p})$, where $\mathrm{p}$ is the total population, we have

$$
\mathrm{dy} / \mathrm{y}=\alpha+\beta \mathrm{dL} / \mathrm{L}-\mathrm{dp} / \mathrm{p} \quad 3
$$

There are two basic assumptions about equation 3 . The first assumption is that there is a decreasing return to scale, which follows from the fact that there is a fixed or slightly variable production factor (for instance, land in an agricultural economy).

$$
\begin{aligned}
& d y / y=a+\beta d p / p-d p / p \\
& d y / y=a+(\beta-1) d p / p
\end{aligned}
$$

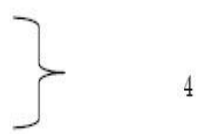

The coefficient $\beta$ being positive, the slope of the regression should in principle be greater than 1 . If it is greater than 0 , it is because returns to scale are increasing, i.e. $\beta>1$. Therefore, the expectation of a negative correlation in the regression is justified if the demand effect is stronger than the supply effect. 


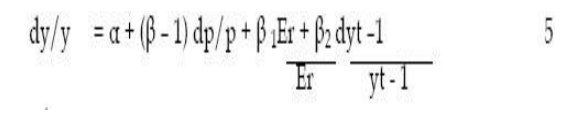

where

Er $=$ Socioeconomic rate

dyt -1 = lagged per capita output

$\beta_{1}$ and $\beta_{2}=$ are expected to be positive

(Buiter, 1988).

\section{DisCUSSION}

There are many impacts of population growth in Mararaban Guruku as well as Africa in general.

\subsection{Economic Growth}

Evidence shows that rapid population growth lowers per capita income growth in most LDCs, especially those that are already poor, dependent on agriculture, and experiencing pressures on land and natural resources (Bloom et al., 2010).

\subsection{Poverty and inequality}

Even though aggregate statistical correlations between measures of poverty and population growth at the national level are often inconclusive, at the household level the evidence is strong and compelling. The negative consequences of rapid population growth fall most heavily on the poor because they are the ones who are made landless, suffer first from cuts in government health and education programs, bear the brunt of environmental damage, and are the main victims of job cuts due to the slower growth of the economy. Poor women once again bear the greatest burden of government austerity programs, and another vicious cycle is set in motion. To the extent that large families perpetuate poverty, they also exacerbate inequality.

\subsection{Education}

Although the data are sometimes ambiguous on this point, it is generally agreed that large family size and low incomes restrict the opportunities of parents to educate all their children. At the national level, rapid population growth causes given educational expenditures to be spread more thinly, lowering quality for the sake of quantity. This, in turn, feeds back on economic growth because the stock of human capital is reduced by rapid population growth (Zeidenberg and Bailey, 2010).

\subsection{Health}

High fertility harms the health of mothers and children. It increases the health risks of pregnancy, and closely spaced births have been shown to reduce birth weight and increase child mortality rates (Burström, et al., 2001).

\subsection{Food}

Feeding the world's population is made more difficult by rapid population growth-over $90 \%$ of additional LDC food requirements are caused by population increases. New technologies of production must be introduced more rapidly, as the best lands have already been cultivated. International food relief programs become more widespread (Yesuf, et al., 2008).

\subsection{Environment}

Rapid population growth contributes to environmental degradation in the form of forest encroachment, deforestation, fuel-wood depletion, soil erosion, declining fish and animal stocks, inadequate and unsafe water, air pollution, and urban congestion (Madu, 2009).

\subsection{International Migration}

Many observers consider the rapid increase in international migration, both legal and illegal, to be one of the major consequences of developing countries' population growth. Though many factors cause migration, an excess of job seekers (caused by rapid population growth) over job opportunities in the LDC economy is surely one of them. However, unlike the first six consequences listed here, some of the economic and social costs of international migration fall on recipient countries- increasingly in the developed world. It is not surprising, therefore, that this issue has recently taken on political importance in North America and Europe. Perhaps the least understood aspect of population growth is its tendency to continue even after the birth rate has declined substantially, it also has impact on the environment (Ayinde, et al., 2013).

\section{CONCLUSION}

Population studies are very vital to the economic development of a nation. Nigeria being a developing country, there is a demand to update population growth and distribution. This study found out that there are two basic aspects of population that have tremendous impact; the negative and positive population growth. The socioeconomic factor has attracted people to settle coupled with the location of the study are near to the Federal Capital Territory. About negative factors consists of high crime rate $37 \%$, insecurity $19 \%$, overpopulation $30 \%$, development of Ghetto and Slum $11 \%$, and unemployment rate $13 \%$. The positive population growth includes; the opening of new areas $10 \%$, around the study such the Fulani Ruga settlement was in the middle of the urban centers, it promotes urbanization $25 \%$, it also aids socialization $12 \%$, increase in taxation $35 \%$, investment and income $6 \%$.

There is a significant and strong correlation between the dependency ratio and the population growth in Mararaban Guruku with about 0.98 and the coefficient of determination of 0.7 . There are great challenges confronting Nigeria, because as the economy is improving so also the human number increases. The reverse is the case in the rural economy where some parts of the country were neglected or marginalized. This theory is more practical in Nigeria today, the state capitals are more developed with socioeconomic activities, while, the Local government areas are left undeveloped. This is clearly visible in the Northern and middle belt of Nigeria. The increase in the rate of consumption has proven that our population is really growing faster than expected

1. There is a need to sensitize public on population and health management, overcrowding might lead to disease outbreak, such as Cholera, Meningitis, and other child-killer diseases

2. The issue of child labour, trafficking, and begging are all product of child abuse. If the tendency Ratio supersedes the family's needs or is high, then there is a likelihood to experience negative consequences in our societies. The more people's number increases, the more the demand to take care of them. Hence, government such checkmate the menace of unwanted population growth aside from the natural increase.

3. Poverty exists in the growing population; to overcome poverty in the growing population it is paramount to introduce different support programs. This will help to prioritize the public on selfreliance and to engage in entrepreneurship.

\section{REFERENCES}

Abu, J., Okwori, J., Ajegi, S.O., Ochinyabo, S. 2015. An empirical investigation of the Malthusian population theory in Nigeria. Journal of Emerging Trends in Economics and Management Sciences, 6 (8), 367-375.

Abubakar, I.R., Dano, U.L. 2018. Socioeconomic challenges and opportunities of urbanization in Nigeria. In Urbanization and Its Impact on Socio-Economic Growth in Developing Regions (pp. 219240). IGI Global.

Adenola, F., Saibu, O.M. 2017. Does population change matter for long-run economic growth in Nigeria? International Journal of Development and Sustainability, 12 (6), 1955-1965.

Ali, H.S., Law, S.H., Zannah, T.I. 2016. The dynamic impact of urbanization, economic growth, energy consumption, and trade openness on $\mathrm{CO} 2$ emissions in Nigeria. Environmental Science and Pollution Research, 23 (12), 12435-12443. 
Aubrecht, C., Steinnocher, K., Huber, H. 2014. DynaPop-Population distribution dynamics as a basis for social impact evaluation in crisis management. In ISCRAM, pp. 319-323.

Ayinde, O.E., Ojehomon, V.E.T., Daramola, F.S., Falaki, A.A. 2013. Evaluation of the effects of climate change on rice production in Niger State, Nigeria. Ethiopian Journal of Environmental Studies and Management, 6 (6), 763-773.

Bloom, D., Finlay, J., Humair, S., Mason, A., Olaniyan, O., Soyibo, A. 2010. Prospects for economic growth in Nigeria: a demographic perspective. In IUSSP Seminar on Demographics and Macroeconomic Performance held at Novotel, Gare de Lyon, Paris, France (pp. 4-5).

Buiter, W.H. 1988. Death, birth, productivity growth and debt neutrality. The Economic Journal, 98 (391), 279-293.

Burström, K., Johannesson, M., Diderichsen, F. 2001. Health-related quality of life by disease and socio-economic group in the general population in Sweden. Health Policy, 55 (1), 51-69.

Cole, M.A., Neumayer, E. 2004. Examining the impact of demographic factors on air pollution. Population and Environment, 26 (1), 5-21.

Davis, K. 1945. The world demographic transition. The Annals of the
American Academy of Political and Social Science, 237 (1), 1-11.

Madu, I.A. 2009. The environmental impacts of regional disparity in population and wealth distribution in Nigeria. Environment, Development and Sustainability, 11 (2), 265-276.

Obioha, E.E. 2008. Climate change, population drift and violent conflict over land resources in northeastern Nigeria. Journal of Human Ecology, 23 (4), 311-324.

Stephenson, J., Newman, K., Mayhew, S. 2010. Population dynamics and climate change: what are the links? Journal of Public Health, 32 (2), 150-156.

Theodore, O.I. 2006. The effects of population growth in Nigeria. Journal of Applied Sciences, 6 (6), 1332-1337.

Yesuf, M., Di Falco, S., Deressa, T., Ringler, C., Kohlin, G. 2008. The impact of climate change and adaptation on food production in low-income countries: evidence from the Nile Basin, Ethiopia. Intl Food Policy Res Inst.

Zeidenberg, M., Bailey, T. 2010. Human Resource Development and Career and Technical Education in American Community Colleges. Community College Research Center, Columbia.

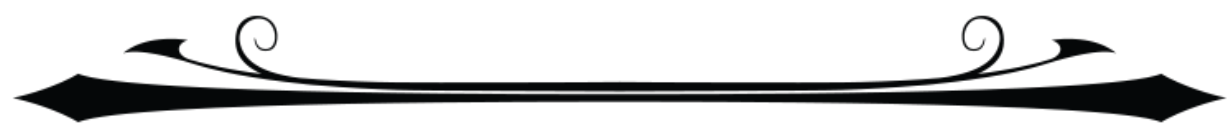

